One- st ep and Non- cat al yt i c I nt r andl ecul ar Redox Reacti ons of Conj ugated Al I E- Di enal s to Non- conj ugat ed Z- Enoi c Aci ds in Subcriti cal Wat er

\begin{tabular}{|l|l|}
\hline 著者 & $\begin{array}{l}\text { Chen Xi n, Sumot o Kana, M tani Sot at Su, } \\
\text { Yamagam Tet suya, Yokoyama Kazuya, Wang } \\
\text { Pengyu, Hi rao Shot aro, N shi waki Nagat oshi , } \\
\text { Kobi ro Kazuya }\end{array}$ \\
\hline $\begin{array}{l}\text { j our nal or } \\
\text { publ i cat i on ti tl e }\end{array}$ & The Journal of Super cr i t i cal Fl ui ds \\
\hline vol une & 62 \\
\hline page r ange & 178 183 \\
\hline year & $2012-02$ \\
\hline URL & ht t p: //hdl . handl e. net /10173/962 \\
\hline
\end{tabular}




\section{One-step and Non-catalytic Intramolecular Redox Reactions of Conjugated All E-Dienals to Non-conjugated Z-Enoic Acids in Subcritical Water}

Xin Chen, Kana Sumoto, Sotatsu Mitani, Tetsuya Yamagami, Kazuya Yokoyama, Pengyu Wang, Shotaro Hirao, Nagatoshi Nishiwaki, Kazuya Kobiro*

School of Environmental Science and Engineering, Kochi University of Technology,

185 Miyanokuchi, Tosayamada, Kami, Kochi 782-8502, Japan

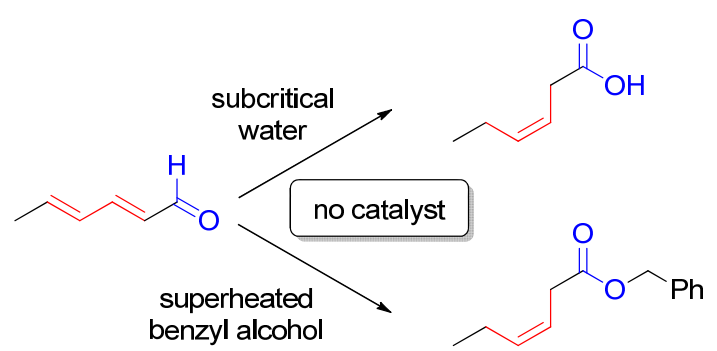

Keywords: Subcritical water; Non-catalytic reaction; One-step reaction; Intramolecular redox 


\section{Hightlights}

1. Non-conjugated unsaturated acid derivatives are obtained by treating conjugated dienals in superheated fluids in one-step.

2. Simple treatment of all E-dienals in superheated fluids produces thermodynamically less-stable $Z$ unsaturated acid derivatives.

3. The obtained non-conjugated unsaturated acid is converted to biologically active $\gamma$-lactone with a hydroxyl group by hydrogen peroxide in one step. 


\section{One-step and Non-catalytic Intramolecular Redox Reactions of Conjugated All E-Dienals to}

Non-conjugated Z-Enoic Acids in Subcritical Water

Xin Chen, Kana Sumoto, Sotatsu Mitani, Tetsuya Yamagami, Kazuya Yokoyama, Pengyu Wang, Shotaro Hirao, Nagatoshi Nishiwaki, and Kazuya Kobiro*

School of Environmental Science and Engineering, Kochi University of Technology,

185 Miyanokuchi, Tosayamada, Kami, Kochi 782-8502, Japan

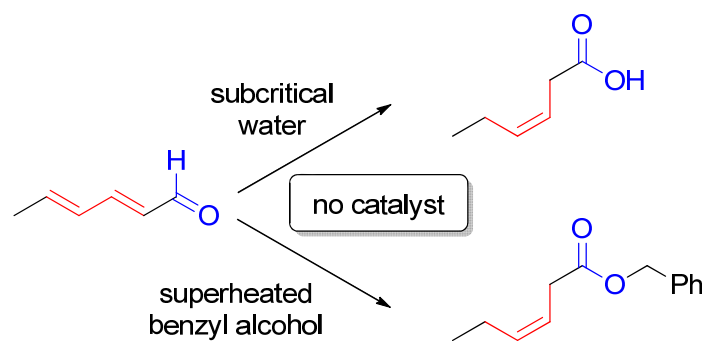

Keywords: Subcritical water; Non-catalytic reaction; One-step reaction; Intramolecular redox

* Corresponding author. Tel.: +81 88757 2503; fax: +81 887572520.

E-mail address: kobiro.kazuya@kochi-tech.ac.jp (K. Kobiro) 


\section{Abstract}

Simple treatment of conjugated all E-dienal, $(2 E, 4 E)$-hexa-2,4-dienal, in subcritical water afforded an intramolecular redox product, non-conjugated Z-enoic acid, (Z)-hex-3-enoic acid, in $42 \%$ yield without the usage of a metal catalyst in one-step under the conditions of $250{ }^{\circ} \mathrm{C}, 10 \mathrm{~min}$, and $0.35 \mathrm{~g} \mathrm{~mL}^{-1}$ water amount. Similar treatment of the dienal in superheated benzyl alcohol produced corresponding ester, benzyl (Z)-hex-3-enoate, in $34 \%$ yield under the conditions of $300{ }^{\circ} \mathrm{C}, 30 \mathrm{~min}$, and $0.5 \mathrm{~g}$ $\mathrm{mL}^{-1}$ benzyl alcohol amount. The obtained (Z)-hex-3-enoic acid was transformed to cis- $\beta$-hydroxy- $\gamma$-ethyl- $\gamma$-lactone in $90 \%$ yield by hydrogen peroxide at $60{ }^{\circ} \mathrm{C}$ for one day under solvent-free conditions. 


\section{Introduction}

Unsaturated acids and their derivatives are important substances to show various bioactivities. For example, naturally occurring unsaturated fatty acids, such as arachidonic, docosahexaenoic, and eicosapentaenoic acids, are quite important bio-precursors that lead to regulating reagents in bodies $[1,2]$. Almost all naturally occurring fatty acids contain the Z-configuration in their double bonds, which is less stable than the E-configuration. In addition, simple (Z)-alk-3-enoic acids bearing one non-conjugated double bond are important in vivo, some of which are pheromones of certain coleopterous insects or intermediates used in their syntheses [3-5]. Moreover, a brominated (Z)-alk-3-enoic acid derivative exhibits cytotoxicity against cultured cells [6]; 3-unsaturated amino acids are known to function as specific enzyme inhibitors and pyridoxal phosphate dependent enzymes [7,8]; and an ester derivative is a potent odorant in Japanese Green Tea [9]. Furthermore, (Z)-alk-3-enoic acid derivatives are the possible precursors of $\gamma$-lactones with alkyl chains exhibiting pheromone characteristics [10].

Intense research to obtain thermodynamically less-stable $Z$ isomers of non-conjugated unsaturated hexenoic acids and their related compounds has led to several methods for 
selective hydrogenation using transition metal complexes. Hydrogenation of sorbic acid catalyzed by $\mathrm{Cr}(\mathrm{CO})_{6}[11]$ or $[\mathrm{Cp} * \mathrm{Ru}]^{+}[12,13]$, which fixes two double bonds of sorbic acid to s-cis conformation in the metal center, is a typical method. The classical P-2 Ni catalyst is also available through the hydrogenation of unsaturated acid bearing a triple bond $[4,5]$. Olefin metathesis using the Grubbs' II catalyst is employed to afford cyclic derivatives containing a double bond with the Z-configuration followed by ring cleavage [14]. Lithium-ammonia reduction of 2-thiophenecarboxylic acid [15] and the addition of alcohol to ketene intermediate from corresponding acid chloride in situ [16] also appeared in the literature.

In contrast, much attention has been paid to superheated fluids such as subcritical water (sub-CW) [17], supercritical water (SCW) [17], and supercritical alcohols [18,19] from the perspective of green reactions because of their unique properties. For example, extremely strong complexation effect under high pressure produces solvent clusters around the solute molecules, which leads to strong interactions between the solute and solvent molecules. In addition, a major characteristic of superheated fluids is that their inherent high temperatures cause vigorous vibration of the molecules in the system, which leads to high reactivity between them. By employing these remarkable properties, intriguing reactions were reported, such as the Beckmann rearrangement of 
cyclohexanone oxime [20], pinacol rearrangement of 2,3-dimethyl-2,3-butanediol [21], and Cannizzaro reaction of formaldehyde [22], acetaldehyde [23,24], and benzaldehyde [25] in SCW without any catalyst. Through the researches, we recently disclosed a series of unique reactions, such as non-catalytic green oxidation of alcohols in SCW without any oxidant to give ketones and hydrogen gas [26], highly selective non-catalytic Oppenauer oxidation of alcohols in SCW [27], the first direct observation of radical species in sub-CW by means of ESR [28], easy permethylation of catechols in SCW [29], and effective aldol reactions in sub-CW [30].

These studies allowed us to delineate the organic transformations of conjugated dienals into non-conjugated unsaturated acids with Z-form by thermal intramolecular rearrangement in superheated fluids. We now present an example of metal-free, non-catalytic, and simple preparation of (Z)-alk-3-enoic acid from (2E,4E)-alka-2,4-dienal in sub-CW. 


\section{Material and methods}

\section{General information.}

(2E,4E)-Hexa-2,4-dienal and (2E,4E)-hexa-2,4-dienol were purchased from Alfa Aesar. Cinnamaldehyde, acetophenone, benzaldehyde, 3-methylbut-2-enal, m-xylene, 2,4-dinitrophenylhydrazine, and benzyl alcohol were purchased from Nacalai Tesque Inc. (2E,4E)-1,5-Diphenylpenta-2,4-dien-1-one, (3E,5E)-6-methylhepta-3,5- dien-2-one and silica gel (Wakogel C-200) were purchased from Wako Pure Chemical Industries Co. Ltd. (2E,4E)-Deca-2,4-dienal, $n$-decane, $n$-dodecane, and $n$-tridecane were obtained from Tokyo Chemical Industry Co. Ltd. They were used as received without further purification. NMR spectra were obtained using Varian UNITY INOVA spectrometer and Bruker AVANCE III 400N (400 MHz). GC-MS analyses were performed on a Shimadzu QP5050 with DB-1 column. GC analyses were performed on a Shimadzu GC-17A and DB-1 or CBP-5 column. Recoveries of reactants (percentage of reactant recovered to that loaded in the reaction) and yields of products were determined by internal standard methods on GC. n-Decane, n-dodecane, and n-tridecane were used as the internal standards. Products were identified by comparing the ${ }^{1} \mathrm{H}$ NMR and/or GC-MS spectra with those of authentic samples. Microwave heating was performed using Anton Paar 
Monowave 300 microwave Synthesis Reactor.

\section{General procedure for reactions in subcritical water.}

$(2 E, 4 E)$-Hexa-2,4-dienal and reverse osmosis water, in which the dissolved oxygen was removed by $\mathrm{N}_{2}$ gas bubbling for $30 \mathrm{~min}$, were introduced into an SUS 316 batch-type reactor $(10 \mathrm{~mL}$ volume). To remove the oxygen in the reactor, the reactor was purged with $\mathrm{N}_{2}$ for 10 min and sealed with a screw cap, which was equipped with a thermocouple for measuring the inner reactor temperature. The reactor was then placed in a molten salt bath, which was maintained at an appropriate temperature and heated for an appropriate time. A period of approximately 20-30 s was required to raise the inner temperature of the reactor to $200-350^{\circ} \mathrm{C}$. The reaction was quenched by placing the reactor into an ice-water bath. The screw cap was opened after the reactor cooled completely. Microwave heating was done in a glass reaction vessel. A period of approximately $3.5 \mathrm{~min}$ was required to raise the temperature of the reactor to $220{ }^{\circ} \mathrm{C}$ and approximately $4.5 \mathrm{~min}$ was required to cool the temperature to $60{ }^{\circ} \mathrm{C}$. The reaction mixture was extracted with ethyl ether three times. The organic phase was separated from the water phase, and the solvent was evaporated in vacuo to produce crude products. These crude products were purified by using silica gel chromatography (Wako 
C-200, ether and hexane) and GPC (JAI gel 1H and 2H, chloroform) when necessary.

\section{Reaction of 2a with hydrogen peroxide.}

A mixture of $34 \mathrm{mg}(0.30 \mathrm{mmol})$ of $(\mathrm{Z})$-hex-3-enoic acid and $150 \mu \mathrm{L}$ of $30 \% \mathrm{H}_{2} \mathrm{O}_{2}$ solution $(1.47 \mathrm{mmol})$ was heated at $60{ }^{\circ} \mathrm{C}$ for 1 day with vigorous stirring. The solvent was removed under reduced pressure to afford $35.4 \mathrm{mg}(0.27 \mathrm{mmol}, 90 \%)$ of cis- $\beta$-hydroxy- $\gamma$-ethyl- $\gamma$-lactone as a single product. 


\section{Results and discussion}

$(2 E, 4 E)$-Hexa-2,4-dienal (1a) was treated in sub-CW under different conditions of reaction temperature, reaction time, and water amount (Scheme 1 and Table 1). When the reaction was performed under the conditions of $250{ }^{\circ} \mathrm{C}, 10 \mathrm{~min}$, and $0.10 \mathrm{~g} / \mathrm{mL}$ water amount, the reaction proceeded smoothly to afford mainly (Z)-hex-3-enoic acid (2a, 29\%) and a by-product 2-methycyclopent-2-enone (3a, 1\%) with 19\% recovery of dienal 1a (entry 4). It is quite noteworthy that the $Z$ isomer of $\mathbf{2 a}$ was easily obtained simply by starting from all $E$ dienal without using any metal catalyst. Interestingly, the diene moiety of 1a was reduced to monoene and the aldehyde moiety was oxidized to carboxylic acid in one step, which is an example of intramolecular redox reactions. For intermolecular redox reactions of aldehydes, the conventional Cannizzaro reaction is well known to simultaneously give a reduction product of alcohol and an oxidation product of acid under strongly basic conditions. However, when the Cannizzaro reaction is performed under sub-CW and SCW conditions, the reaction proceeds even without a catalyst [22-25]. For intramolecular redox reaction of conjugated enals, unique catalytic intramolecular redox reactions of enals affording saturated acids as well as lactones were reported [31]. However, our reaction is, to the best of our knowledge, the first 
example of non-catalytic intramolecular Cannizzaro reaction of dienals affording non-conjugated unsaturated acids 2a. When the reaction was performed at a low temperature $\left(200{ }^{\circ} \mathrm{C}\right)$, only a small amount of $\mathbf{2 a}$ with a trace amount of 3a was obtained (entry 1). The yield of 2a increased with temperature up to $250{ }^{\circ} \mathrm{C}$, while a higher temperature $\left(350{ }^{\circ} \mathrm{C}\right)$ did not yield the product (entries $1,5,8$, and 9). These results indicate that the reaction has high activation energy and that the products are not stable at high temperatures. Prolonged heating caused isomerization to yield a conjugated acid with higher stability, (E)-hex-2-enoic acid (4a), and $\gamma$-ethyl- $\gamma$-lactone (5a), which should be derived from the cyclization of $2 \mathbf{a}$ or $\mathbf{4 a}$ under the reaction conditions (entry 7). It is noteworthy that no product was produced in the absence of water (entry 3), indicating water plays a critical role in the reaction. In addition, water amount dependence was observed for the formation of 2a (entries 3-6) at the fixed temperature $\left(250^{\circ} \mathrm{C}\right)$ and in fixed reaction time $(10 \mathrm{~min})$, suggesting solubility of $1 \mathrm{a}$ to water is improved till $0.35 \mathrm{~g} \mathrm{~mL}^{-1}$ water amount. The best result was achieved under the conditions of $250{ }^{\circ} \mathrm{C}, 10 \mathrm{~min}$, and $0.35 \mathrm{~g} / \mathrm{mL}$ water amount to afford $2 \mathrm{a}$ in $42 \%$ yield with a trace amount of 3a (1\%) (entry 5). Microwave heating instead of molten salt bath resulted in similar yield of $\mathbf{2 a}$ (entry 2). 


\section{Scheme 1.}

Reactions of (2E,4E)-hexa-2,4-dienal (1a) and (2E,4E)-deca-2,4-dienal (1b) in sub-CW.

\section{Table 1}

Reaction of (E,E)-dienal 1a in sub-CW.

When the present reaction was applied to $(2 E, 4 E)$-deca-2,4-dienal (1b) with a long alkyl chain under similar reaction conditions of $250{ }^{\circ} \mathrm{C}, 30 \mathrm{~min}$, and $0.35 \mathrm{~g} / \mathrm{mL}$ water amount, corresponding (Z)-dec-3-enoic acid (2b), which is a precursor of a $\gamma$-lactone derivative exhibiting pheromone character [11], was nicely obtained in $20 \%$ yield. For conjugated ketone derivatives such as (2E,4E)-1,5-diphenylpenta-2,4-dien-1-one (6) and (3E,5E)-6-methylhepta-3,5-dien-2-one (10), however, a remarkable difference in reaction behavior was observed to continuously produce retro-aldol products cinnamaldehyde (7), acetophenone (8), benzaldehyde (9), and 3-methylbut-2-enal (11) in addition to a cyclization product, m-xylene (12). Judging from these results, the aldehyde group is indispensable for the intramolecular redox reactions and the cyclization. The formation of $\mathbf{1 2}$ can be explained by thermal electrocyclic reaction of a $6 \pi$ electron system of enol generated by tautomerism of $\mathbf{1 0}$ followed by dehydration $[32,33]$. 


\section{Scheme 2.}

Reaction of dienones in sub-CW.

Concerning the formation of cyclopentenones, Miller et al. reported the reaction of dienal derivatives via Nazarov-type cyclization or hetero $[\pi 4 \mathrm{a}+\pi 2 \mathrm{a}]$ concerted bond formation [34]. However, the critical differences between their and our reactions are the configuration of double bonds in the reactants and the use of catalysts. The researchers specifically used $2 Z, 4 E$-isomer as a substrate in dichloromethane in the presence of strong Lewis acids as catalysts, while we used $2 E, 4 E$-isomer and only water without any catalyst. Similar cyclization was reported for the congested dienal with plural sterically bulky groups via a ketene intermediate as a special case [35]; however, non-substituted simple dienal 1a was used in our reaction.

As plausible reaction pathways, we propose two possibilities via ketene intermediate (pathway A) and gem-diol intermediate (pathway B), both of which include $[1,5]$ hydrogen shift as the key step (Scheme 3). Thermal reactions yielding Z-configuration of double bonds employ [1,5]hydrogen shift as a well-established methodology. Interesting applications of [1,5]hydrogen shift recently appeared as a key 
process for the activation of $\mathrm{C}-\mathrm{H}$ bonds, although the reactions required acid catalysts [36,37]. Intermediate I can be produced via Michael addition of water followed by the $E / Z$ isomerization of a double bond and dehydration. Further hydration of intermediate $\mathbf{I}$ would afford gem-diol intermediate II (Scheme 3). Theoretical considerations by DFT calculations suggested a plausible reaction pathway via $[1,5]$ hydrogen shift leading to a ketene intermediate III (Scheme 4). The activation energy from the intermediate I to the transition state TS-1 is calculated to be $26.3 \mathrm{kcal} / \mathrm{mol}$. Once the ketene intermediate III is generated, water can be easily added to produce carboxylic acid 2a. As an additional possibility, we supposed the reaction pathway via gem-diol intermediate II because aldehyde intermediate I can be easily hydrated in high-pressure water to produce intermediate II (Scheme 3). Similar DFT calculation indicates that the pathway leading to the transition state TS-2 from the gem-diol intermediate II requires slightly higher activation energy of $30.8 \mathrm{kcal} / \mathrm{mol}$ (Scheme 4). The resulting intermediate $\mathbf{I V}$ would get tautomerism to produce non-conjugated acid 2a. Thus, high-density water molecules of sub-CW seem not to participate in the key step of the reaction, while sub-CW can play several important roles at once required for the reaction; such as i) a green reaction medium (solvent), ii) an effective heat-transferring material tolerating quite drastic atmosphere, and iii) an indispensable reactant affording the acid. 


\section{Scheme 3.}

Plausible reaction pathways from $1 \mathbf{a}$ to $2 \mathbf{a}$.

\section{Scheme 4.}

Activation energies of the reactions via a ketene intermediate (pathway A) and a gem-diol intermediate (pathway B). (Numbers are relative energies in $\mathrm{kcal} / \mathrm{mol}$ calculated by DFT B3LYP/6-31G* plus zero-point vibrational energy)

According to the reaction pathway proposed in Scheme 3, the reaction in superheated alcohol instead of sub-CW should afford a corresponding ester instead of the acid. The reaction of 1a in high-temperature benzyl alcohol $\left(300{ }^{\circ} \mathrm{C}, 30 \mathrm{~min}\right.$, and $0.2 \mathrm{~g} / \mathrm{mL}$ alcohol amount) actually yielded corresponding ester, benzyl (Z)-hex-3-enoate (13), in $31 \%$ yield as expected, concomitant with benzyl (E)-hex-2-enoate (14) in $4 \%$ and (2E,4E)-hexa-2,4-dienol (15) in 5\% yield (Scheme 5 and Table 2). Alcohol 15 should be produced by Meerwein-Ponndorf-Verley (MPV) reduction of aldehyde 1a in the presence of a large excess amount of benzyl alcohol because the reaction conditions were the variant of representative non-catalytic MPV reduction [19]. Thus, it is truly 
noteworthy that the ester was obtained as a main product from aldehyde directly even though under MPV reduction conditions.

\section{Scheme 5.}

Reaction of (E,E)-dienal 1a in superheated benzyl alcohol.

\section{Table 2}

Reaction of 1a in superheated benzyl alcohol.

The bifunctionality of the unsaturated acid prompted us to further study chemical transformation. $\mathrm{A} \mathrm{C}=\mathrm{C}$ bond of an alkene is generally oxidized by peracid such as $m \mathrm{CPBA}$ or by a combination of hydrogen peroxide and acid. Thus, intramolecular oxidation appears to be possible when unsaturated acids are treated with hydrogen peroxide under solvent-free conditions; however, oleic acid, a typical unsaturated acid, is intact upon heating with hydrogen peroxide at $60{ }^{\circ} \mathrm{C}$. In contrast, $\beta, \gamma$-unsaturated acid 2a efficiently reacted under the same conditions to afford cis- $\beta$-hydroxy- $\gamma$-ethyl- $\gamma$-lactone (16) [38] in 90\% yield (Scheme 6). It is considered that intramolecular oxidation readily proceeds, leading to epoxide $\mathbf{1 8}$ when $\mathbf{2 a}$ is converted to peracid 17 by hydrogen peroxide. The successive ring expansion is caused by 
participation of the carboxyl group to form a lactone framework, although an additional pathway via diol 19 is possible. This reaction does not require a solvent or a reagent other than hydrogen peroxide and furnishes cis- $\gamma$-lactone $\mathbf{1 6}$ as a single isomer, which is promising for application to organic syntheses.

\section{Scheme 6.}

Tandem intramolecular oxidation-ring expansion affording cis- $\gamma$-lactone 16. 


\section{Conclusions}

In summary, the organic one-step transformation of conjugated dienals into non-conjugated unsaturated acid derivatives was achieved in superheated fluids. It is of importance that thermodynamically less-stable $Z$ isomers of unsaturated acid derivatives were produced mainly by simple treatment of all E-dienals in superheated fluids. In addition, the obtained non-conjugated unsaturated acid was converted to the biologically active $\gamma$-lactone with a hydroxyl group by hydrogen peroxide in one step. 


\section{Acknowledgements}

This work was supported in part by Kyoto-Advanced Nanotechnology Network from the Ministry of Education, Culture, Sports, Science and Technology, Japan and by Adaptable and Seamless Technology transfer Program through target-driven R\&D (A-STEP) from Japan Science and Technology Agency. The authors thank Prof. Dr. Kiyomi Kakiuchi, Nara Institute of Science and Technology, for the measurement of HRMS. 


\section{References}

[1] H. Iso, K.M. Rexrode, M.J. Stampfer, J.E. Manson, G.A. Colditz, F.E. Speizer, C.H. Hennekens, W.C. Willett, Intake of fish and omega-3 fatty acids and risk of stroke in women, J. The American Medical Association 285 (2001) 304-312.

[2] F. Darios, B. Davletov, Omega-3 and omega-6 fatty acids stimulate cell membrane expansion by acting on syntaxin 3, Nature 440 (2006) 813-817.

[3] H. Fukui, F. Matsumura, M.C. Ma, W.E. Burkholder, Identification of the sex pheromone of the furniture carpet beetle, anthrenus flavipes leconte, Tetrahedron Letters 15 (1974) 3563-3566.

[4] J.G. Millar, A.C. Oehlschlager, J.W. Wong, Synthesis of two macrolide aggregation pheromones from the flat grain beetle, cryptolestes pusillus (Schönherr), The J. Organic Chemistry 48 (1983) 4404-4407.

[5] A.C. Oehlschlager, J.W. Wong, V.G. Verigin, H.D. Pierce, Synthesis of two macrolide pheromones of the rusty grain beetle, cryptolestes ferrugineus (Stephens), The J. Organic Chemistry 48 (1983) 5009-5017.

[6] S. Aratake, A. Trianto, N. Hanif, N.J. De Voogd, J. Tanaka, A new polyunsaturated brominated fatty acid from a haliclona sponge, Marine Drugs 7 (2009) 523-527. 
[7] R.V.J. Chari, J. Wemble, A simple, efficient synthesis of $\beta$-methylene phenylalanine. A new approach to the preparation of $\beta, \gamma$-unsaturated $\alpha$-amino acid enzyme substrate analogs, Tetrahedron Letters 20 (1979) 111-114.

[8] D.B. Berkowitz, J.A. Pumphrey, Q. Shen, Enantiomerically enriched $\alpha$-vinyl amino acids via lipase-mediated "reverse transesterification", Tetrahedron Letters 35 (1994) 8743-8746.

[9] K. Kumazawa, H. Masuda, Identification of potent odorants in Japanese green tea (Sen-cha), J. Agricultural Food Chemistry 47 (1999) 5169-5172.

[10] L.-A. Garbe, K. Morgenthal, K. Kuscher, R. Tressl, Metabolism of deuterated erythro-dihydroxy fatty acids in saccharomyces cerevisiae: enantioselective formation and characterization of hydroxylactones, Helvetica Chimica Acta 91 (2008) 993-1007.

[11] A.A. Vasil'ev, E.P. Serebryakov, Catalytic hydrogenation/enzymic hydrolysis as a route from alkyl alka-2,4-dienoates to (Z)-alk-3-enoic acids, Mendeleev Communications 4 (1994) 4-5.

[12] H.G. Niessen, D. Schleyer, S. Wiemann, J. Bargon, S. Steines and B. Driessen-Hoelscher, In situ PHIP-NMR studies during the stereoselective 
hydrogenation of sorbic acid with a $[\mathrm{Cp} * \mathrm{Ru}]^{+}$catalyst, Magnetic Resonance in Chemistry 38 (2000) 747-750.

[13] E. Leitmannová, R. Malá, L. Červený, Notes on selectivity aspects in sorbic acid and sorbic alcohol hydrogenation, Research on Chemical Intermediates, 35 (2009) 63-69.

[14] A. Baron, P. Verdié, J. Martinez, F. Lamaty, cis-Apa: a practical linker for the microwave-assisted preparation of cyclic pseudopeptides via RCM cyclative cleavage, The J. Organic Chemistry 76 (2011) 766-772.

[15] W.G. Blenderman, M.M. Joullié, G. Preti, Lithium/ammonia reductions of 2-thiophenecarboxylic acids, The J. Organic Chemistry 48 (1983) 3206-3213.

[16] G. Cardillo, A. De Simone, A. Mingardi, C. Tomasin, Synthesis of $\beta$, $\gamma$-unsaturated esters from $\alpha, \beta$-unsaturated acid chlorides, Synlett 11 (1995) $1131-1132$.

[17] H. Weingartner, E.U. Franck, Supercritical water as a solvent, Angewandte Chemie International Edition 44 (2005) 2672-2692.

[18] L. Sominsky, E. Rozental, H. Gottlieb, A. Gedanken, S. Hoz, Uncatalyzed Meerwein-Ponndorf-Oppenauer-Verley reduction of aldehydes and ketones under supercritical conditions, The J. Organic Chemistry 69 (2004) 1492-1496. 
[19] A. Daimon, T. Kamitanaka, N. Kishida, T. Matsuda, T. Harada, Selective reduction of unsaturated aldehyde to unsaturated alcohols using supercritical 2-propanol, The J. Supercritical Fluids 37 (2006) 215-219.

[20] O. Sato, Y. Ikushima, T. Yokoyama, Noncatalytic Beckmann rearrangement of cyclohexanone-oxime in supercritical water, The J. Organic Chemistry 63 (1998) 9100-9102.

[21] Y. Ikushima, K. Hatakeda, O. Sato, T. Yokoyama, M. Arai, Noncatalytic organic synthesis using supercritical water: the peculiarity near the critical point, Angewandte Chemie International Edition 38 (1999) 2910-2914.

[22] M. Osada, M. Watanabe, K. Sue, T. Adschiri, K. Arai, Water density dependence of formaldehyde reaction in supercritical water, The J. Supercritical Fluids 28 (2004) 219-224.

[23] Y. Nagai, C. Wakai, N. Matubayasi, M. Nakahara, Noncatalytic Cannizzaro-type reaction of acetaldehyde in supercritical water, Chemistry Letters 32 (2003) $310-311$.

[24] Y. Nagai, S. Morooka, N. Matubayasi, M. Nakahara, Mechanisms and kinetics of acetaldehyde reaction in supercritical water: noncatalytic disproportionation, 
condensation, and decarbonylation, The J. Physical Chemistry A 108 (2004) 11635-11643.

[25] Y. Ikushima, K. Hatakeda, O. Sato, T. Yokoyama, M. Arai, Structure and base catalysis of supercritical water in the noncatalytic benzaldehyde disproportionation using water at high temperatures and pressures, Angewandte Chemie International Edition, 40 (2001) 210-213.

[26] P. Wang, H. Kojima, K. Kobiro, K. Nakahara, T. Arita, O. Kajimoto, Reaction behavior of secondary alcohols in supercritical water, Bulletin of the Chemical Society of Japan, 80 (2007) 1828-1832.

[27] P. Wang, X. Shi, K. Kataoka, Y. Maeda, K. Kobiro, Non-catalytic oppenauer oxidation of alcohols in supercritical water, The J. Supercritical Fluids 52 (2010) $222-227$.

[28] K. Kobiro, M. Matsura, H. Kojima, K. Nakahara, The first ESR observation of radical species in subcritical water, Tetrahedron 65 (2009) 807-810.

[29] P. Wang, K. Kobiro, Subcritical water assisted clean cross-aldol reactions, J. Chemical Engineering of Japan 44 (2011) 577-582. 
[30] P. Wang, D. Nishimura, T. Komatsu, K. Kobiro, Simple, non-catalytic permethylation of catechol derivatives in subcritical and supercritical water, The J. Supercritical Fluids 58 (2011) 360-364.

[31] S.S. Sohn, J.W. Bode, Catalytic generation of activated carboxylates from enals: a product-determining role for the base, Organic Letters 7 (2005) 3873-3876.

[32] T. Zimmermann, G.W. Fischer, Pyryliumverbindungen. 31 [1]. Reaktion 3-alkylsubstituierter 2,4,6-triaryl-pyryliumsalze mit 1,3-diketonaten: ein weg zur darstellung 3-acylsubstituierter benzophenone, J. für Praktische Chemie 328 (1986) 359-372.

[33] A.T. Balaban, A. Tudose, M.T. Caproiu, Synthesis of 2,4-dimethyl-6-oxo-2,4-heptadienoic acid from 2,4,6-trimethylpyrylium salts, Tetrahedron 59 (2003) 3291-3295.

[34] A.K. Miller, M.R. Banghart, C.M. Beaudry, J.M. Suh, D. Trauner, Development of novel Lewis acid catalyzed cycloisomerizations: synthesis of bicyclo[3.1.0]hexenes and cyclopentenones, Tetrahedron 59 (2003) 8919-8930.

[35] H. Ogawa, Y. Taketugu, T. Imoto, Y. Taniguchi, H. Kato, Novel rearrangement of twisted 2,4-di-alkyl 2-trans-4-trans pentadienals: an approach to cyclopentenones 
based on molecular mechanical consideration, Tetrahedron Letters 20 (1979) 3457-3460.

[36] M.C. Haibach, I. Deb, C.K. De, D. Seidel, Redox-neutral indole annulation cascades, J. The American Chemical Society 133 (2011) 2100-2103.

[37] K. Mori, S. Sueoka, T. Akiyama, Expeditious construction of a carbobicyclic skeleton via sp3-C-H functionalization: hydride shift from an aliphatic tertiary position in an internal redox process, J. The American Chemical Society 133 (2011) 2424-2426.

[38] I. Shibata, F. Matsuo, A. Baba, H. Matsuda, Synthesis of hydroxy lactones by bis(tributyltin) oxide promoted ring expansion of halo lactones, The J. Organic Chemistry 56 (1991) 475-476. 


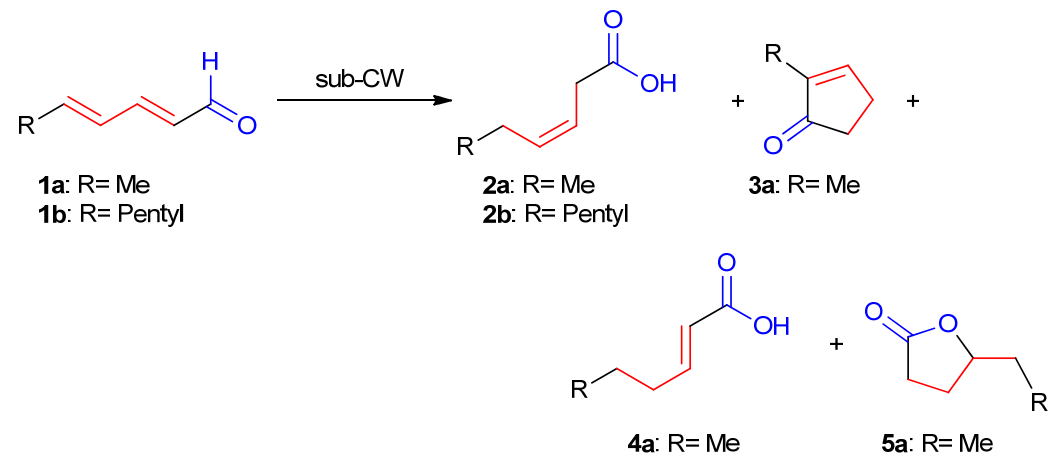

Scheme 1. Reactions of (2E,4E)-hexa-2,4-dienal (1a) and (2E,4E)-deca-2,4-dienal (1b) in sub-CW. 

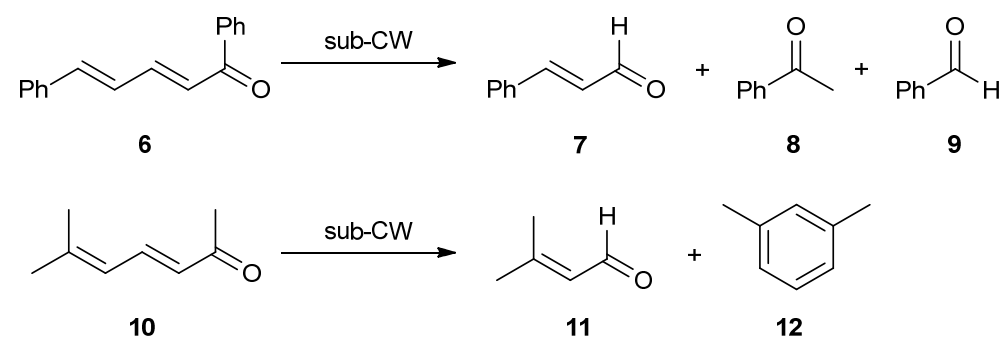

Scheme 2. Reaction of dienones in sub-CW. 


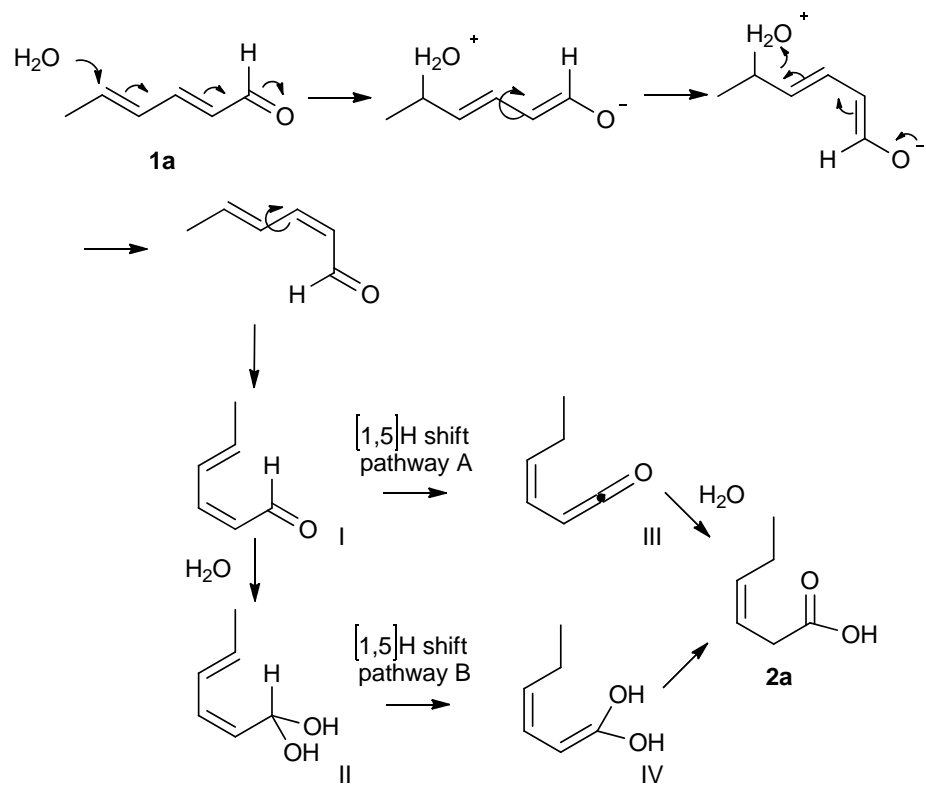

Scheme 3. Plausible reaction pathways from 1a to $\mathbf{2 a}$. 


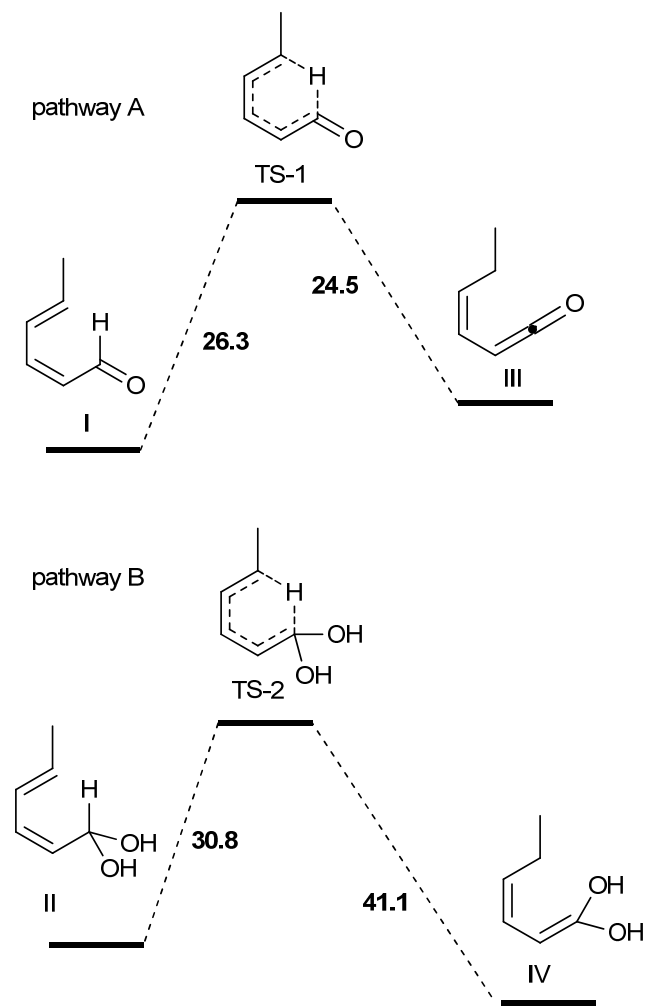

Scheme 4. Activation energies of the reactions via a ketene intermediate (pathway A) and a gem-diol intermediate (pathway B). (Numbers are relative energies in $\mathrm{kcal} / \mathrm{mol}$ calculated by DFT B3LYP/6-31G* plus zero-point vibrational energy) 


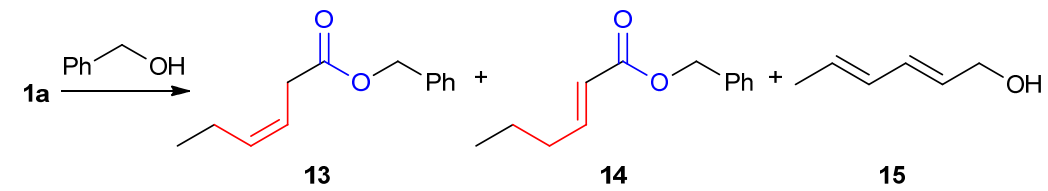

Scheme 5. Reaction of (E,E)-dienal 1a in superheated benzyl alcohol. 


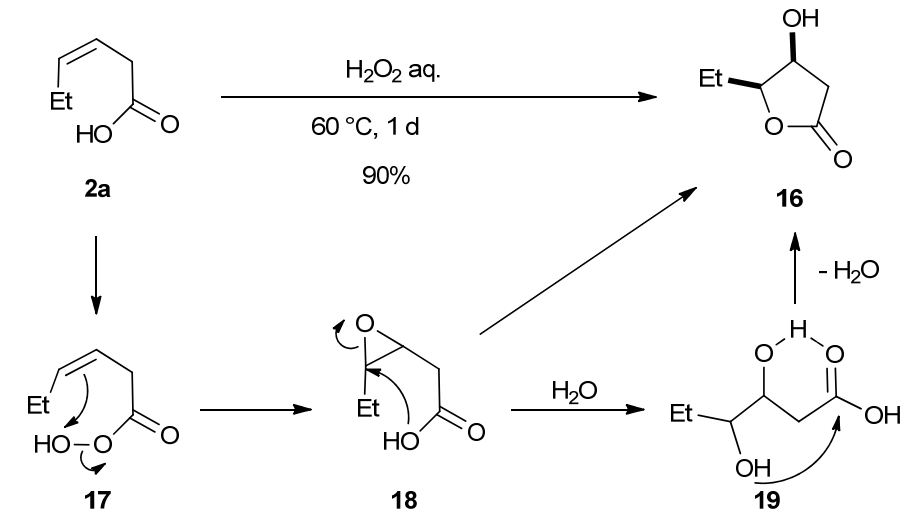

Scheme 6. Tandem intramolecular oxidation-ring expansion affording cis- $\gamma$-lactone 16. 


\section{Table 1}

Reaction of (E,E)-dienal 1a in sub-CW. ${ }^{\mathrm{a}}$

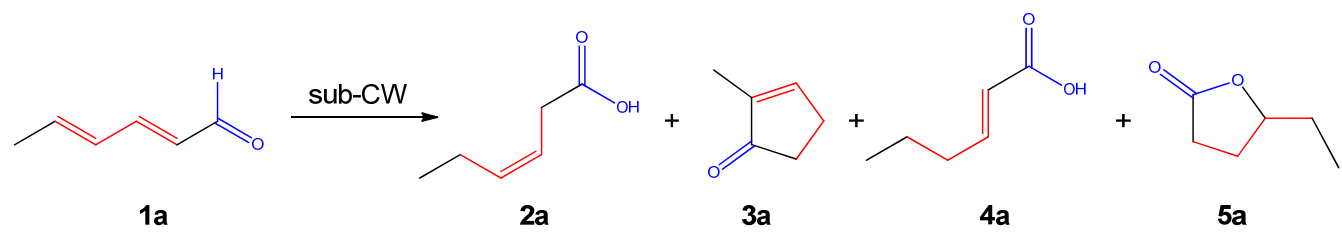

\begin{tabular}{ccccccccc}
\hline Entry & \multirow{2}{*}{$\begin{array}{c}\text { Temperature } \\
\left({ }^{\circ} \mathrm{C}\right)\end{array}$} & $\begin{array}{c}\text { Water } \\
\text { amount } \\
\left(\mathrm{g} \mathrm{mL}^{-1}\right)^{\mathrm{b}}\end{array}$ & $\begin{array}{c}\text { Time } \\
(\mathrm{min})\end{array}$ & $\begin{array}{c}\text { Recovery } \\
\text { of 1a (\%) }\end{array}$ & \multicolumn{5}{c}{ Yield (\%) } & 2a & 3a & 4a & 5a \\
\hline 1 & 200 & 0.35 & 10 & $58(3)$ & $3(0.9)$ & $1(0.1)$ & - & - \\
$2^{\mathrm{c}}$ & 220 & 0.35 & 30 & $7(2)$ & $37(3)$ & $3(0.1)$ & - & - \\
3 & 250 & 0 & 10 & $43(2)$ & - & - & - & - \\
4 & 250 & 0.10 & 10 & $19(3)$ & $29(0.2)$ & $1(0.2)$ & - & - \\
5 & 250 & 0.35 & 10 & $11(3)$ & $42(0.5)$ & $1(0.6)$ & - & - \\
6 & 250 & 0.40 & 10 & $8(0.8)$ & $36(3)$ & $1(0.3)$ & - & - \\
7 & 250 & 0.35 & 30 & - & $32(2)$ & $2(0.2)$ & $10(0.7)$ & $3(0.3)$ \\
8 & 300 & 0.35 & 10 & - & $5(0.9)$ & - & $2(0.4)$ & - \\
9 & 350 & 0.35 & 10 & - & - & - & - & - \\
\hline
\end{tabular}




\section{Table 2}

Reaction of 1a in superheated benzyl alcohol. ${ }^{\mathrm{a}}$

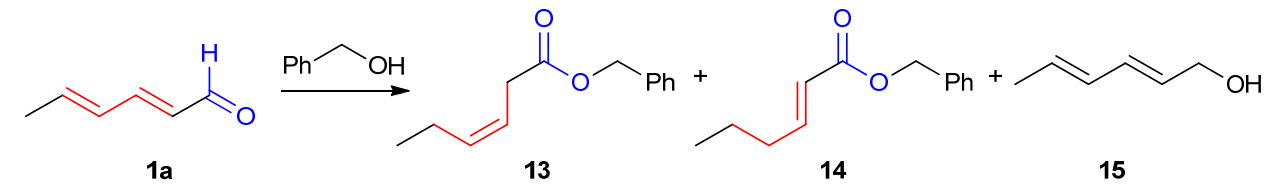

\begin{tabular}{cccccc}
\hline \multirow{2}{*}{ Entry } & $\begin{array}{c}\text { Alcohol } \\
\text { amount } \\
\left(\mathrm{g} \mathrm{mL}^{-1}\right)^{\mathrm{b}}\end{array}$ & $\begin{array}{c}\text { Recovery } \\
\text { of 1a (\%) }\end{array}$ & \multicolumn{3}{c}{ Yield (\%) } \\
\cline { 5 - 7 } $1^{\mathrm{c}}$ & 0.15 & $80(4)$ & $2(0.2)$ & - & $\mathbf{1 3}$ \\
$2^{\mathrm{d}}$ & 0.15 & $25(7)$ & $18(1)$ & - & - \\
3 & 0.15 & - & $32(0.3)$ & $4(2)$ & $4(0.1)$ \\
4 & 0.2 & - & $31(2)$ & $4(0.2)$ & $5(1)$ \\
5 & 0.3 & - & $31(4)$ & $4(0.2)$ & $8(2)$ \\
6 & 0.4 & - & $32(1)$ & $5(1)$ & $9(1)$ \\
7 & 0.5 & - & $34(1)$ & $4(0.6)$ & $13(0.5)$ \\
\hline
\end{tabular}

a $100 \mathrm{mg}(1.04 \mathrm{mmol})$ of $\mathbf{1 a}$ was reacted at $300{ }^{\circ} \mathrm{C}$. Mean value is given for a minimum of three runs. Standard deviation is shown in parentheses. Reaction time was $30 \mathrm{~min}$.

${ }^{\mathrm{b}}$ Alcohol amount was defined as the weight of benzyl alcohol $(\mathrm{g})$ /reactor volume $(\mathrm{mL})$.

${ }^{\mathrm{c}}$ Reaction temperature at $200{ }^{\circ} \mathrm{C}$.

${ }^{\mathrm{d}}$ Reaction temperature at $250^{\circ} \mathrm{C}$. 